papers, mostly on the specific heats of solids and other questions of thermodynamies, and on atomic spectra.

He has told me how he came to make his great discovery. With his work on spectra he was using, of course, Bohr's orbit theory, but he always felt that the quantum conditions in this theory were unsatisfactory and that atomic spectra should really be determined by some kind of eigenvalue problem. In 1924, de Broglie published his work on waves associated with the motion of free particles. This influenced Schrödinger profoundly, and he set to work to try to generalize de Broglie waves to bound particles. $\mathrm{H}_{\mathrm{e}}$ finally obtained a neat solution of the problem, leading to the appearance of the energy-levels as eigenvalues of a certain operator. $\mathrm{H}_{\theta}$ immediately applied his method to the electron in the hydrogen atom, duly taking into account relativistic mechanics for the motion of the electron, as de Broglie had done. The results were not in agreement with observation. We know now that Schrödinger's method was quite correct, and the discrepancy was due solely to his not having taken the spin of the electron into account. However, electron spin was unknown at that time, and Schrödinger was very disappointed and concluded that his method was no good and abandoned it. Only after some months did he roturn to it, and then noticed that if he treated the electron nonrelativistically his method gave results in agreement with observation in non-relativistic approximation. $\mathrm{He}$ wrote up this work and published it in 1926, and in this delayed manner Schrödinger's wave equation was presented to the world.

A short time previously Heisenberg had discovered his matrix mechanics, another formalism for dealing with atomic processes. The theories of Heisenberg and Schrödinger were soon found to be equivalent, there being a mathematical transformation that converts one into the other. Two independent and apparently entirely different lines of thought thus led to the same foundation for atomic physics.

Schrödinger published a series of papers in quick succession, developing his ideas. For this work he shared the Nobel Prize in Physics for 1933.

In 1927 he unfortunately moved to Berlin, where he became Planck's successor. In consequence his life became disturbed by political developments, and with Hitler's coming to power in 1933, he decided he could not continue in Germany. He came to England, and for a while held a followship at Oxford. In 1936 he was offered a situation at Graz. He was well aware of the uncertain position of Austria at that time, and it was a difficult decision for him to make; but the attraction of returning to his native country outweighed his caution and he accepted.

With the German annexation of Austria in 1938 Schrödinger was immediately in difficulty, because his leaving Germany in 1933 was taken to be an unfriendly act. He was forced to express his approval of the Nazi regime, and he did this in as ambiguous a way as he could (see Nature, 141, 929 ; 1938).

$\mathrm{He}$ soon found life with the Nazis intolerable, and, profiting by the fact that they had neglected to take away his passport in the first place, he was able to slip across the frontier to Italy. He proceeded to Princeton University and after a short stay there moved to Dublin, to the newly created Institute for Advanced Studies, where he became director and remained until his retirement in 1955 .

All this time Schrödinger continued his research and published many papers on a variety of topics. Some of them were concerned with unifying gravitation and electromagnetism, the problem which absorbed Einstein for many years and which is still unsolved. Schrödinger remained greatly interested in the foundations of atomic physics. $\mathrm{H}_{\Theta}$ did not like the generally accepted dual description in terms of waves and particles, with a statistical interpretation for the waves, and tried to set up a theory in terms of waves only. This led him into controversy with other leading physicists.

Schrödinger was unconventional in his way of life. When he went to the Solvay conferences in Brussels, he would walk from the station to the hotel where the delegates stayed, carrying all his luggage in a rucksack on his back and looking so like a tramp that it needed a great deal of argument at the reception desk before he could claim the room that had been reserved for him.

After his retirement he returned to an honoured position in Vienna. He died after a long illness. $\mathrm{H}_{\theta}$ is survived by his wife, who was his faithful companion throughout their marriage.

P. A. M. Dirac

\section{Dr. Sidney Marsh}

Dr. S. Marsh, who was head of the Physics Department of Battersea Polytechnic from 1919 until 1950, died on December 14, at the age of seventy-six.

After completing a double first in physics and mathematics at University College, Cardiff, he went to Munich and Göttingen, where he obtained his Ph.D. on work on discharge tubes under Prof. E. Riecke. He joined the staff of Battersea Polytechnic in 1909 and, except for the two years 1917-19, when he was head of the Mathematics and Physics Department at Rutherford Technical College, Newcastle on Tyne, he remained there until his death. He was appointed head of the Department in 1919, and, after his retirement in 1950, he continued as a part-time lecturer giving more than part-time service. He gave his last lecture on December 12, 1960, two days beforo his death. The way he continued to adapt himself to the rapidly changing conditions of work in the post-war period was very remarkable. Old regulations and new regulations, general and special degree, polytechnic and college of advanced technology, he took it all in his stride.

His research interests lay in electrolysis and gas discharges, but the passion of his life was teaching, and, while this goes unrecorded in the proceedings of learned journals, it lives on in the hearts and minds of all those that passed through his Department during his long stay there. With immense energy he also threw himself into the examination work of the University of London, and for many years right up to his death he was the mainstay of the external examinations in physics. Marsh must have been a name to countless students, the world over, who never knew of the immense pains he took to be fair to them and the compassion with which he carried out his duties as an examiner.

As a young man taking over what had been his Department for so long, I might have expected to find him a little difficult as a colleague. Far from this being so, he was a most kindly and considerate person who was never obtrusive with his advice, though always willing to give it. He had that true humility that is a token of true greatness, and those who have known him and have worked with him mourn his loss greatly. L. R. B. ELTON 


$$
\text { Mr. H. T. Pledge, C.B.E. }
$$

By the death of Mr. H. T. Pledge on December 28, the library and scientific worlds have suffered a great loss.

Humphrey Thomas Pledge, son of Thomas Pledge, was born on November 6,1903 . He went to Tonbridge School and thence as an Exhibitioner to Trinity College, Cambridge, where he took a first in the Natural Sciences Tripos. After a short period of teaching at Wrekin College he entered the Science Museum Library as an assistant keeper in 1928.

During his early years in the Library, Pledge was concerned with its services to industry, both in lend. ing and in providing information. It was during this time that he collected material for his major work, published by H.M. Stationery Office in 1939, under the title Science since 1500. This is a comprehensive and masterly historical survey of the development of the physical and biological sciences, which has been widely accepted as a standard book of reference. It has been reprinted three times in Great Britain and has also been published in the United States.
In 1945, Pledge became keeper of the Science Museum Library, and the full burden of the restoration of its services after their dislocation during the War fell on his shoulders. Later developments which added to his administrative responsibilities were the photocopying service and the impact on the Science Museum Library of the formation of the National Scientific Lending Library to take over gradually the former's lending service to industry. During his tenure of the keepership he continued to build up the Library into one of the finest scientific libraries in Britain, in spite of stringent limitations on the financial resources available to him.

Pledge's interests were wide, ranging from biography through the physical and biological sciences to ethnology and archæology, and his knowledge was deep. His book brought fellow workers on the history and philosophy of science from all over the world to South Kensington to visit him. He took an active part in the founding of the British Society for the Histo ry of Science.

In 1934, Pledge married Ruth, daughter of the Rev. H. M. Brown, and they had one daughter. He was made a C.B.E. in 1960.

\section{NEWS and VIEWS}

\section{U.S. Atomic Energy Commission : \\ Dr. Glenn T. Seaborg}

Dr. Glenn Theodore Seaborg, who has been appointed chairman of the U.S. Atomic Energy Commission, was born in Ishpeming, Michigan, on April 19, 1912. After graduating at the University. of California in chemistry in 1934, Dr. Seaborg held various research and teaching appointments in that University until 1942, when he was appointed section chief in the Manhattan Engineer District's Metallurgical Laboratory at the University of Chicago, where he conducted research in nuclear chemistry and physics; here he was responsible for developing the process used for the separation of plutonium from fuel elements irradiated in the production reactors at the Hanford installation at Richland, Washington. In 1946 he returned to the University of California at Berkeley as a professor in the Department of Chemistry. $\mathrm{He}_{\Theta}$ was appointed chancellor of the University in 1958.

While serving as instructor at the University of California in 1940, Dr. Seaborg was co-discoverer of element 94 (plutonium), the first of a number of trans-uranic elements which his research activitios revealed over the next fifteen years. He was the discoverer in 1941 of the isotope used as a source of nuclear energy, plutonium 239; in 1942 of the uranium isotope, uranium 233 ; in 1944 of elements 95 (americium) and 96 (curium); co-discoverer in 1949 of element 97 (berkolium); co-discoverer in 1950 of element 98 (californium); in 1952 of element 99 (einste nium); in 1953 of element 100 (fermium); and in 1955 of element 101 (mendelevium). He was a member of the Atomic Energy Commission's General Adv'sory Committee from 1946 until 1950; member of the Joint Commission of Radioactivity, International Council of Scientific Un'ons, since 1946 ; and of the Committee of Standards and Units of Radioactivity, National Research Council, sinco 1947.
Anatomy and Biology at Western Reserve University

Prof. Marcus Singer has been appointed Henry Willson Payne professor of anatomy in Western Reserve University, Cleveland, Ohio. He is at present professor of zoology and of child development and family relationships in Cornell University. Prof. Howard A. Schnoiderman, associate professor of biology in Cornell University, has been appointed professor of biology in Western Reserve University. Both appointments will be effective July 1, 1961.

A native of Pittsburgh, Prof. Singer first graduated from the University of Pittsburgh, and later was awarded M.A. and Ph.D. degrees by Harvard University. $\mathrm{He}$ was on the Harvard staff during 1938-51, first in the Biology and Zoology Departments and later in the Anatomy Department of the Medical School. In 1950 he served as visiting professor at the Long Island College of Medicine in Brooklyn, New York. He went to Cornell as associate professor of zoology and of child development and family relationships in 1951 and became a full professor in 1953.

Prof. Schneiderman is a native of New York City. Ho attended Swarthmore College and Columbia University and graduated from the former in 1948 with honours in mathematics and natural sciences. He was granted the degree of M.A. and a doctorate by Harvard Unjversity. During 1952-53 he was a University research fellow in biology at Harvard. In 1953 he was appointed assistant professor of zoology at Cornoll and was appointed associate professor in 1956.

\section{Botany at Calcutta : Prof. S. M. Sircar}

Dr. S. M. Sircar has recently been appointed Sir Rashbehari Ghosh professor of botany in the University of Calcutta. This chair, created in 1914 in the name of its donor, is the oldest in Indian universities for fostering research work in botany 